\section{OS PROGRAMAS DE GEOGRAFIA NO ENSINO SECUNDĀRIO} EM FRANÇA (COMEÇO DO SKECULO XIX - 1980)

O trabalho que ora se apresenta é a tese elaborada por MARIA

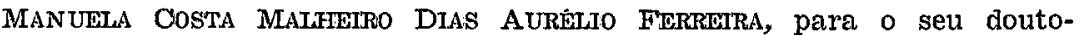
mento de Terceiro Ciclo, brilhantemente defendida na Universidade de Paris VII, em 24 de Novembro de 1980 , perante um júri formado pelos Professores O. Dollfus, PH. Pinchemel e A. Haumont. São dois tomos, em forma dactilografada e policopiada, com o título geral de Les programmes de Géographie dans l'enseignement secondaire en France (début du 19ème siècle - 1980). O primeiro abrange as páginas 1 a 65 , e ainda $\mathrm{xx}$ p. com notas e documentos; o segundo tem as páginas 66 a 477 , e LXV p. de notas e anexos. Ambos incluem informações estatisticas e abundante bibliografia criteriosamente escolhida ( $\left.{ }^{1}\right)$.

A primeira parte é consagrada ao estudo de alguns aspectos do sistema educativo francês e aos problemas ligados com a democratização do ensino, de modo a ajudar a compreender as transformaçóes actuais do ensino secundário e, sobretudo, as que tiveram reflexos importantes no da Geografia. Os ensinos pré-elementar e elementar são analisados através das suas caracteristicas pedagógicas, dos efectivos de alunos, dos problemas levantados pela Reforma de 1975. De modo análogo é apresentado o ensino secundário: as suas estruturas $e$ as reformas, os niveis de orientação escolar criados pela Reforma de 1959 e posteriores, os meios de funcionamento e as consequências sociais. Quadros com dados esiatísticos e gráficos ilustram o volume, tendo também a valorizá-lo as numerosas notas (p. I-VI) e documentos em anexo (p. vII-xx).

O segundo tomo é, sem dúvida, o mais interessante: La science géographique et l'enseignement de la Géographie dans le secondaire en France. Na Introdução a Autora esclarece que o seu objectivo «était de connaître l'évolution de l'enseignement de la geéographie dans le secondaire, pendant les XIXème et XXème slècles, fondamentalement à travers une analyse des programmes officiels mais également d'une analyse d'autres types de documents. Parmi ces documents ceux qui sont relatifs au corpus scientifique de la géographie et à son évolution

(1) Colocamos na biblioteca do Centro de Estudos Geográficos de Lisboa o exemplar que nos foi oferecido, de modo a poder ser consultado por quantos se interessam por tal assunto. sont nécessairement très représentés, le choix même du sujet l'impliquait». A Parte $A$, «Une brève histoire de l'évolution de la science géographique en France» (pp. 67-101), contém os seguintes subtítulos: 1. Les fondateurs de la géographie moderne (la géographie avant Vidal de La Blache; l'cuvre de Vidal de La Blache), 2. L'essor de l't̂́cole de géographie française. 3. La spécialisation. 4. La Nouvelle géographie. A Parte B, a mais substancial do volume (p. 102-470), «L'enseignement de la Géographie dans le secondaire en France (1802-1980)», engloba três capítulos: I. Un développement peu homogène (1802-1902); II. La stabilisation (1902-1976); III. Intégration ou renouvellement?. A antecedê-los diz a Autora, «Nous allons maintenant nous occuper de l'enseignement de la géographie dans le secondaire en France, mais nous ferons des références aux autres niveaux d'enseignement, toutes les fois qu'elles nous sembleront nécessaires pour expliquer les transformations qui ont eu lieu dans l'enseignement de cette discipline au niveau secondaire. Comme nous l'avons dit antérieurement, nous essaierons également de mettre en évidence les relations entre le développement de la géographie comme science et celui de son évolution dans l'enseignement. Nous soulignerons d'autre part les transformations du système scolaire qui ont eu des conséquences importantes en ce qui concerne l'enseignement de la géographie». O volume termina com uma interessante Conclusão geral (p. 471-477), de que os pontos principais são os seguintes: o periodo antes de 1870, quando a Geografia não era mais que uma disciplina auxiliar da História; as importantes modificações trazidas pela Reforma do ensino de 1902 (ainda que as ideias «vidalianas» tivessem tido algumas dificuldades em se imporem no ensino secundário); a predominância das preocupações pedagógicas, relativamente às científicas (as Reformas de 1874, de 1902 e de 1975). "D'après nous, l'enseignement de la géographie en France et la part faite à chacune des branches de la discipline restent toujours conditionnées par la liaison de cet enseignement à celui cle l'histoire et de l'instruction civique et à. l'inexistence de programmes plus adaptés à chacune des sections du Second cycle» (p. 477).

Os assuntos da Parte B estão estudados com bastante pormenor e as informações coligidas, quer no texto, quer nas notas em fim de volume, mostram o interesse e o cuidado postos pela Autora na preparação da tese. Ainda que longo, não resistimos a transcrever o enunciacio dos títulos. Assim, no Capítulo I aparecem os seguintes: 1. Avant 1870 2. Après 1870: Les idées et les hommes (l'enquête de Levasseur et Himiy; les programmes de 1874; Emile Levasseur; Ludovic Drapeyron; Franz Schrader; les Sociétés de Géographie; Paul Vidal de La Blache); Les obstacles au développement de l'enseignement de la géographie. 3. Les aspects fondamentaux qui ont caractérisé l'enseignement de la géographie pendant la période considérée (1802-1902): les buts assignés à l'enseignement de la géographie; la place de la géographie dans le plan d'études; la géographie dans l'enseignement secondaire classique (les programmes; la liaison de l'enseignement de la géographie avec les autres disciplines; les méthodes d'enseignement et le matériel pédagogique); less programmes 
de l'enseignement spécial; les programmes de l'enseignement secondaire féminin; le baccalauréat. 4. La formation des professeurs de géographie. 5. Conclusion. Ao Capitulo II correspondem: 1. Un développement unifié (1902-1976); la réforme de 1902; l'enseignement de la géographie dans la réforme de 1925; les réformes des annés 30. 2. La période 1940-1944. 3. La période 1945-1976; les «classes nouvelles»; l'évolution des programmes. 4. L'évolution de quelques aspects fondamentaux de l'enseignemen de la géographle pendant la période considérée (1902-1976): les buts de l'enseignement de la géographie; les programmes; la liaison de l'enseignement avec les autres disciplines; les méthodes d'enseignement et le matériel pédagogique; la critique des programmes. 5. La formation des professeurs. 6. Conclusion. O Capitulo III, «Intégration ou renouvellement?», contém: 1. Les activités d'éveil à l'école élémentaire. 2. Le premier cycle: les recherches préparatoires; quelques aspects de la réforme du système éducatif de 1975 (les nouveaux horaires, objectifs, programmes et instructions; les nouveaux manuels); les réactions à la réforme; conclusion. 3. Le second cycle: les recherches; les programmes expérimentaux; les propositions des spécialistes; les programmes de 1980; le problème du baccalauréat; conclusion. 4. La formation des professeurs; conclusion.

Conhecemos a Autora da tese descle que foi nossa aluna em cadeiras da licenciatura de Geografia, na Faculdade de Letras da Universidade de Lisboa. Temos acompanhado as suas actividades, quer durante o tempo em que permaneceu em Paris, quer as do estágio actual no Institut of Education, da Univerisidade de Londres, onde adquire outros conhecimentos e prepara uma tese de doutoramento sob a orlentação do Professor NoRMaN J. Graves, especialista de grande reputação e director do Departamento de Geografia. Perante as provas já dadas, esperamos que num futuro próximo Maria Manubia Costa MaLfitiro Dias aurétio FERREIRA possa também debruçar-se sobre os programas de Geografia no ensino secundário em Portugal, numa altura em que estão acumuladas tantas experiencias. 